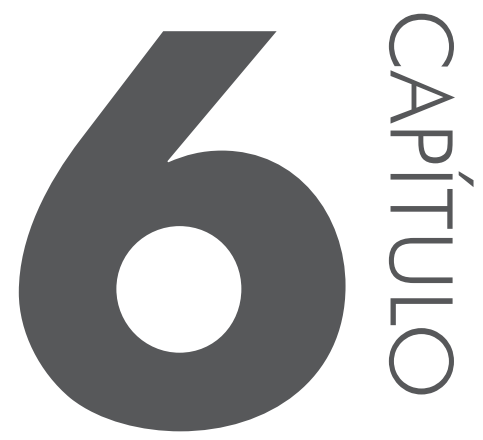

\title{
FARINHAS DE QUINOA, DE LINHAÇA DOURADA E DE SOJA EM BISCOITOS DOCE SABOR COCO
}

Geovana Piveta Ribeiro

Neusa Fátima Seibel

\section{INTRODUÇÃO}

A demanda por alimentos nutritivos e seguros tem crescido rapidamente, principalmente devido à divulgação de que a ingestão de alimentos balanceados constitui-se na maneira correta de evitar ou mesmo corrigir problemas de saúde, as quais muitas vezes têm origem em erros alimentares (SILVA et al., 2011). Tendo em vista a deficiência geral de alimentos com elevada qualidade nutricional, qualquer procedimento que possa melhorar esse valor pode ser interessante (MIRANDA; EL-DASH, 2002). Com isso, têm sido desenvolvidos alimentos funcio- 
nais, pela incorporação de fibras e/ou antioxidantes ou pela redução do teor de gordura (PAUCAR-MENACHO et al., 2008). Cândido e Campos (2005) definem alimentos funcionais como "qualquer alimento ou bebida que, consumidos na alimentação cotidiana, podem trazer benefícios fisiológicos específicos, graças à presença de ingredientes fisiologicamente saudáveis".

Os consumidores estão cada vez mais esclarecidos acerca dos ingredientes que são utilizados nos produtos, o que tem impulsionado o crescimento de produtos de panificação naturais e saudáveis, contendo ingredientes com benefícios adicionais para a saúde. Nesse contexto, os biscoitos fortificados e funcionais merecem destaque (ADITIVOS E INGREDIENTES, 2013). Em meio aos ingredientes alternativos utilizados, as farinhas provenientes de diferentes grãos têm sido empregadas, pois, além de fornecer proteínas, vitaminas e minerais, proporcionam a incorporação de fibras alimentares, contribuindo para a redução do risco de doenças cardiovasculares, obesidades e diabetes (BUENO, 2012).

Dentre as farinhas de oleaginosas, ressaltam-se as farinhas de quinoa, linhaça e soja. A quinoa é um cereal com proteínas de alta qualidade e ausência de glúten, com níveis elevados de ácidos graxos essenciais e boa estabilidade à oxidação, e é um ótimo substituto da farinha de trigo na produção de alimentos para os consumidores celíacos (CALDERELLI et al., 2010). A linhaça é uma semente que possui compostos fisiologicamente ativos, considerada fonte de fibras, de ômega-3 e de lignanas. Seu consumo tem sido associado à prevenção de algumas doenças e a benefícios nutricionais (OLIVEIRA; PIROZI; BORGES, 2007). Já a soja é considerada excelente fonte de proteínas para fortificar produtos de trigo, isso por meio da complementação de aminoácidos e do aumento no conteúdo de proteínas totais (CABALLERO-CÓRDOBA; WANG; SGARBIBIERI, 1994).

Muitos produtos podem ser usados como veículos para o enriquecimento nutricional; dentre eles, salientam-se os biscoitos, pelas facilidades tecnológicas que propiciam ao comportarem grandes opções de ingredientes e formulações, assim como também grande flexibilidade quanto a matérias-primas e características do produto final (MARETI; GROSSMANN; BENASSI, 2010). Entende-se por biscoito o "produto obtido pela mistura de farinha(s), amido(s) e ou fécula(s) com outros ingredientes, submetidos a processos de amassamento e cocção, fermentados ou não" (BRASIL, 2005). Independentemente de sua origem, trata-se de um produto consumido internacionalmente por todas as classes sociais (MORAES et al., 2010).

Há vários estudos que mostram a utilização de farinhas de oleaginosas na obtenção de produtos alimentícios enriquecidos nutricionalmente. Borges et al. (2003) testaram farinha de quinoa em formulação de macarrão pré-cozido. Seus resultados apontaram o aumento no teor de proteínas, cinzas e fibras. Do mesmo modo, Maciel, Pontes e Rodrigues (2008) desenvolveram biscoito tipo cracker 
com adição de farinha de linhaça. Os resultados indicaram que a adição da farinha promoveu um incremento nos teores de proteínas, minerais e fibras alimentares. Vasconcelos et al. (2006) processaram pães de forma com adição de farinha de soja e fibra alimentar visando à obtenção de um produto com propriedades funcionais. Os pesquisadores verificaram que houve elevação no teor de fibras do produto final. Com base nesses dados, este trabalho visou a elaborar e caracterizar farinhas de quinoa, de linhaça e de soja para desenvolver formulações de biscoitos doces sabor coco com as respectivas farinhas.

\section{BISCOITOS}

Biscoitos são "produtos obtidos pelo amassamento e cozimento conveniente de massa preparada com farinhas, amidos, féculas, fermentados ou não, e outras substâncias alimentícias”. Devem ser fabricados a partir de matérias-primas sãs e limpas, isentas de matérias terrosas e parasitas, devendo estar em perfeito estado de conservação e apresentar cor, cheiro e sabor próprios. Os biscoitos malcozidos, queimados e de caracteres sensoriais anormais devem ser rejeitados (BRASIL, 1978).

Embora não constitua um alimento básico como o pão, os biscoitos são aceitos e consumidos por pessoas de qualquer idade, e sua longa vida útil permite que sejam produzidos em grande quantidade e largamente distribuídos (MORAES et al., 2010). Além disso, apresentam-se também como um bom veículo para farinhas mistas. Para que os biscoitos apresentem boa qualidade, a farinha utilizada precisa apresentar certas características tecnológicas apropriadas. A massa produzida não deve ser excessivamente elástica, e o nível de substituição da farinha por outra irá depender do tipo e qualidade da farinha utilizada, do tipo do biscoito, da formulação e dos procedimentos empregados (EL-DASH; GERMANI, 1994). Todos os biscoitos passam basicamente pelas mesmas etapas de processamento: mistura, formação, cozimento, resfriamento e empacotamento (VITTI; GARCIA; OLIVEIRA, 1988).

\subsection{Trigo}

O trigo é um cereal consumido em grande escala, e as cultivares desenvolvidas devem ter o potencial de produzir uma farinha que atenda as especificidades do produto final, as características de crescimento, textura, sabor e coloração desejada, extensibilidade, e, ainda, teor de glúten (MITTELMANN et al., 2000). Serve de matéria-prima para a elaboração de alimentos consumidos diariamente na forma de pães, biscoitos, bolos e massas (SCHEUER et al., 2011).

Farinha de trigo é o produto obtido a partir da espécie Triticumseativan ou de outras espécies do gênero Triticum reconhecidas (exceto Triticumdurum) através do proces- 
so de moagem do grão de trigo beneficiado, e poderá ser acrescido outros componentes, de acordo com o especificado na presente norma (BRASIL, 1996).

No Brasil, 55\% do seu uso se destinam à panificação, e o percentual restante se divide em $17 \%$ para uso doméstico, $15 \%$ para a produção de massas alimentícias, $11 \%$ para a fabricação de biscoitos e $2 \%$ para outros usos, como produtos de confeitaria (EMBRAPA TRIGO, 2013).

De forma geral, a farinha de trigo é composta de carboidratos (78\%), água $(13,41 \%)$, proteínas $(13,40 \%)$ e outros constituintes menores, como fibras (3,46\%), lipídeos (1,47\%) e cinzas (0,67\%) (PEREZ; GERMANI, 2004).

\subsection{Quinoa}

A quinoa, considerada um pseudocereal, tem como principal característica a qualidade de sua proteína, sendo reconhecida pela Organização Mundial de Saúde como um alimento ideal, por sua composição nutricional ser superior à maioria dos cereais (SILVA et al., 2011). Segundo Borges et al. (2010), seu consumo no Brasil ainda é limitado em virtude do alto custo do grão importado, do desconhecimento da população, de hábitos e costumes tradicionais de cereais como arroz, trigo e milho e da baixa disponibilidade de cultivares adaptadas às condições locais.

É um dos grãos mais nutritivos utilizados como alimento humano, e foi selecionado pela FAO (Food and Agriculture Organization) como uma das culturas destinadas a oferecer segurança alimentar neste século. Seu valor nutricional proteico é comparável ao da proteína do leite e seus teores de lisina, metionina e cisteína são maiores do que em cereais e leguminosas comuns, tornando-se complementar a essas culturas, além de conter ácidos graxos benéficos e um alto teor de tocoferóis (FOOD AND AGRICULTURE ORGANIZATION, 1998 ${ }^{1}$ apud REPO-CARRASCO-VALENCIA; SERNA, 2011).

Comercialmente, o grão encontra-se disponível nas formas integral ou polido, farinhas e flocos, podendo ser consumido cozido, em sopas, saladas, cereais matinais e inúmeras outras preparações alimentícias. Sua farinha pode ser utilizada na elaboração de mingaus, pudins, produtos de panificação e massas alimentícias (BORGES et al., 2012). Lopes et al. (2009) analisaram a composição físico-química da farinha de quinoa, registrando teores de $11,15 \%$ de umidade, $11,52 \%$ de proteínas, $5,12 \%$ de lipídeos, 3,72\% de fibras alimentares, 3,49\% de cinzas totais e $65 \%$ de carboidratos, confirmando sua alta qualidade nutricional.

1 FOOD AND AGRICULTURE ORGANIZATION - FAO. Underutilized Andean Food Crops. Rome: FAO, 1998. 


\subsection{Linhaça}

A linhaça é a semente do linho (Linum usitatissimum L.), da família Linaceae, uma planta nativa do oeste asiático e do mediterrâneo. Possui em sua composição química cerca de $30 \%$ a $40 \%$ de gordura, $20 \%$ a $25 \%$ de proteínas, $20 \%$ a $28 \%$ de fibra alimentar total, $4 \%$ a $8 \%$ de umidade e $3 \%$ a $4 \%$ de cinzas, vitaminas A, B, D e E, além de minerais (OLIVEIRA; PIROZI; BORGES, 2007).

$\mathrm{Na}$ última década, seu consumo vem aumentando e despertando o interesse de muitos pesquisadores, porque a linhaça contém combinações funcionais como o ALA (ácido linolênico), lignanas e fibras que estão relacionados ao seu potencial benéfico à saúde (MACIEL; PONTES; RODRIGUES, 2008). Borges et al. (2010) descreve que a linhaça apresenta composição proteica comparável à soja em termos de aminoácidos indispensáveis na dieta: altos teores de ácido aspártico, glutamina, leucina e arginina, além de ser considerada um alimento funcional, pois, além das suas propriedades nutricionais inerentes à sua composição química, atua também na redução de risco de doenças crônicas não transmissíveis, por conter componentes antioxidantes e anticancerígenos.

Segundo Marques et al. (2011), 4,1\% a 12\% de linhaça pode ser usada como ingrediente na alimentação sem riscos à saúde, na forma in natura, inteiro ou moído, acrescentado diretamente sobre alimentos, tais como as frutas, o leite ou o iogurte, ou pode também ser utilizada como ingrediente na preparação de pães, biscoitos, sobremesas, feijão e produtos cárneos.

Como todos os vegetais, existem muitas variedades na mesma família. No que se refere à linhaça, a marrom e a dourada são as mais conhecidas (MOLENA-FERNANDES et al., 2010). A marrom é a mais cultivada, serve de matéria-prima para as indústrias, alimentação animal e humana; e a dourada é uma variedade que cresce melhor em clima frio, porém sua produção é menor, e seu cultivo tem como objetivo a alimentação humana. Em todas as variedades, são encontrados os mesmos elementos: fibras, vitaminas, minerais, aminoácidos e os ácidos graxos ômegas; porém, na linhaça dourada, esses elementos estão em uma proporção e qualidade adequadas ao consumo humano (LIMA, 2007).

\subsection{Soja}

A soja (Glycine max (L.) Merrill.) e os seus produtos vêm sendo amplamente estudados devido não somente ao seu valor nutricional, mas, também, devido às suas propriedades funcionais na indústria de alimentos, como alimento funcional, porque exerce ação moduladora em determinados mecanismos fisiológicos através de suas proteínas e isoflavonas (CIABOTTI et al., 2006). Ela pertence à família das papilonáceas e à subordem das leguminosas, cujos grãos são ricos 
em proteínas $(38 \%)$ e lipídeos (18\%), podendo originar diversos produtos para alimentação humana, como soja cozida, alimentos dietéticos, farinha não desengordurada, manteiga de soja, entre outros (DE ABREU et al., 2007).

Entretanto, seu uso como ingrediente na obtenção de produtos alimentícios tem sido limitado pelo seu sabor de "feijão cru", causado pela atividade da lipoxigenase durante o rompimento do grão de soja. O Brasil, mesmo sendo o segundo maior produtor de soja do mundo, destina apenas $3 \%$ da sua produção à alimentação humana - a maior parte é exportada e usada para ração animal (KINOUCHI et al., 2002).

Numerosas tentativas têm sido feitas com a finalidade de melhorar o sabor dos derivados da soja, e, dentre essas, se destacam: moagem do grão com água quente de $80^{\circ} \mathrm{C}$ a $100{ }^{\circ} \mathrm{C}$; branqueamento; moagem do grão em baixo $\mathrm{pH}$ seguido de cozimento; e maceração do grão em meio alcalino (WANG et al., 1999). O branqueamento consiste em um pré-tratamento com água quente ou vapor, aplicado a frutas e vegetais com a finalidade principal de inativar algumas enzimas, remover parte dos açúcares redutores, evitando ou diminuindo o escurecimento não-enzimático (REIS, 2007), eliminação de odores e sabores desagradáveis, redução da carga microbiana superficial, eliminação do oxigênio dos tecidos, entre outros (MATOS, 2007). Além do branqueamento, uma alternativa para otimizar o consumo humano de soja é a elaboração de produtos derivados, e a farinha de soja é o seu produto menos refinado, porém, é o industrializado mais importante, pois é usada para enriquecer alimentos e para obtenção de texturizados, concentrados e isolados (DANTAS et al., 2010).

\subsection{Alimentos funcionais}

São considerados alimentos funcionais aqueles que, além de fornecerem a nutrição básica, promovem a saúde. Esses alimentos agem por meio de mecanismos não previstos pela nutrição convencional, devendo ser salientado que esse efeito se restringe à promoção da saúde e não à cura de doenças (SANDERS, $1998^{2}$ apud SAAD, 2006). A Anvisa (Agência Nacional de Vigilância Sanitária) define como um alimento com propriedade funcional: "aquela substância relativa ao papel metabólico ou fisiológico que o nutriente e/ou não nutriente tem no crescimento, desenvolvimento, manutenção e/outras funções normais do organismo humano". Para tanto, devem fazer parte da alimentação usual, proporcionando efeitos benéficos sem a necessidade de acompanhamento médico, não devem ser tóxicas, mesmo após a suspensão da ingestão devem continuar promovendo efei-

2 SANDERS, M.E. Overview of functional foods: emphasis on probiotic bacteria. Int. Dairy J., Amsterdam, v.8, p.341-347, 1998. 
to e não devem se destinar a tratar ou curar doenças, estando seu papel ligado à redução do risco de contrair doenças (BRASIL, 1999).

Há vários fatores que podem influenciar seu consumo, e podem ser citados fatores internos, tais como motivação para a compra, os aprendizados, a personalidade de cada pessoa, assim como fatores externos, como a classe social, família, cultura. Dentre esses fatores, os consumidores optam pela prevenção em vez da cura e estão mais interessados na relação entre a saúde e a nutrição e no desejo de combater os males causados por microrganismos e agentes químicos no ar, na água e nos alimentos, além do aumento das evidências científicas sobre a sua eficácia (BASHO; BIN, 2010).

Roberfroid (2002) cita as principais características dos alimentos funcionais: a) devem ser alimentos convencionais e serem consumidos na dieta normal; b) devem ser compostos por componentes naturais; c) devem ter efeitos positivos além do valor básico nutritivo, promovendo benefícios à saúde além de aumentar a qualidade de vida; d) a alegação da propriedade funcional deve ter embasamento científico; e) pode ser um alimento natural ou um alimento no qual um componente tenha sido removido; f) pode ser um alimento onde a natureza de um ou mais componentes tenha sido modificada; g) pode ser um alimento no qual a bioatividade de um ou mais componentes tenha sido modificada.

A importância para a saúde do uso desses alimentos verifica-se no Brasil pelo fato de que os brasileiros enfrentam um avanço das doenças crônicas degenerativas por conta de um estilo de vida desequilibrado, que envolve maus hábitos alimentares e sedentarismo. O consumo regular desses alimentos pode ser uma alternativa para conter o avanço dessas doenças e fazer com que as pessoas se conscientizem que a alimentação tem um papel fundamental sobre a saúde delas. Vale lembrar que esses alimentos somente funcionam quando fazem parte de uma dieta equilibrada, e o risco que existe na ingestão deste tipo de alimento restringe-se somente em não obter os resultados esperados, já que esses alimentos não possuem contraindicação (CARDOSO; OLIVEIRA, 2008).

\section{MATERIAIS E MÉTODOS}

Para a formulação dos biscoitos, foram processadas farinhas de quinoa, linhaça dourada e soja. Esses grãos foram obtidos em loja de produtos naturais e foram selecionados visualmente, sendo utilizados apenas grãos inteiros, sem rachaduras ou manchas. As cascas não foram retiradas, pois o objetivo era obter farinhas integrais. A farinha de trigo utilizada foi comercial (farinha de trigo tipo 1 - moinho de trigo Arapongas LTDA.). Acrescentado às farinhas, foram utilizados polvilho doce, açúcar refinado, margarina sem sal, ovos, coco ralado fresco sem açúcar e essência artificial de baunilha, também adquiridos em comércio local. 


\subsection{Obtenção das farinhas}

As farinhas de linhaça e quinoa foram obtidas pela trituração dos grãos em liquidificador doméstico (marca Mallory) e moinho elétrico (MDR301 - Cadence) seguida de peneiramento em 40 mesh (marca Mallory). A farinha de soja foi obtida seguindo a metodologia usada por Ciabotti et al. (2006). Primeiramente, os grãos foram adicionados a um recipiente de aço inox com água em ebulição por cinco minutos; após, foram resfriados em água fria corrente, triturados em liquidificador, secos em estufa a $65^{\circ} \mathrm{C}$ com circulação de ar por aproximadamente quatro horas, moídos em moinho elétrico (MDR301 - Cadence) e peneirados em 40 mesh (marca Mallory) (Figura 6.1). Depois de prontas, as farinhas foram distribuídas separadamente em embalagens plásticas e armazenadas em local seco e fresco.

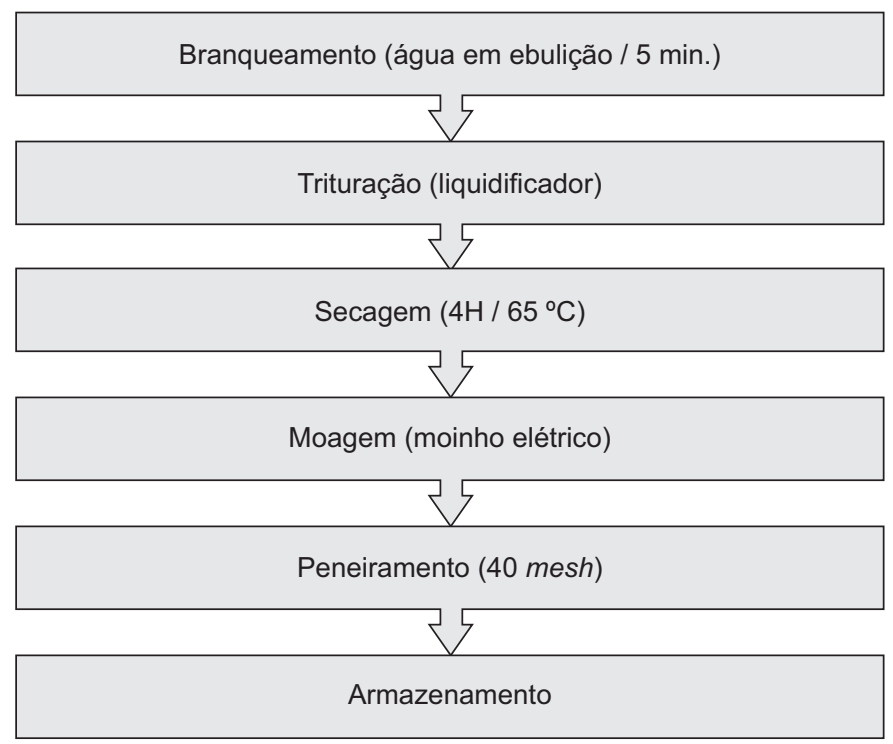

Figura 6.1 Diagrama de blocos do processamento da farinha integral de soja

\subsection{Elaboração dos biscoitos}

Os biscoitos foram elaborados tendo como base a receita para biscoitos de coco com farinha de soja da Embrapa Soja (2013). Para as formulações, foram utilizadas as mesmas proporções de farinha e dos demais ingredientes (Tabela 6.1).

Depois de pesados todos os ingredientes, os ovos, a margarina e o açúcar foram homogeneizados em batedeira doméstica (marca Arno) em velocidade média até a formação de um creme homogêneo, e foi acrescentada a essência artificial de baunilha. 
Tabela 6.1 Formulações dos biscoitos doces sabor coco $(\mathrm{g} / 100 \mathrm{~g})$

\begin{tabular}{ccccc}
\hline & \multicolumn{5}{c}{ Formulações dos biscoitos } \\
\hline Ingredientes & Trigo & Quinoa & Linhaça dourada & Soja \\
\hline Polvilho doce & 32 & 32 & 32 & 32 \\
Açúcar refinado & 18 & 18 & 18 & 18 \\
Tipo de farinha & 18 & 18 & 18 & 18 \\
Margarina & 14,7 & 14,7 & 14,7 & 14,7 \\
Ovos & 10 & 10 & 10 & 10 \\
Coco ralado & 7 & 7 & 7 & 7 \\
Essência de baunilha & 0,3 & 0,3 & 0,3 & 0,3 \\
\hline
\end{tabular}

Em seguida, adicionou-se o polvilho, o coco ralado e a respectiva farinha, e misturou-se com as mãos até obter uma massa uniforme. A massa foi moldada, distribuída em assadeira untada e levada para assar em forno industrial (marca Dako) a $200{ }^{\circ} \mathrm{C}$ por aproximadamente trinta minutos (Figura 6.2).

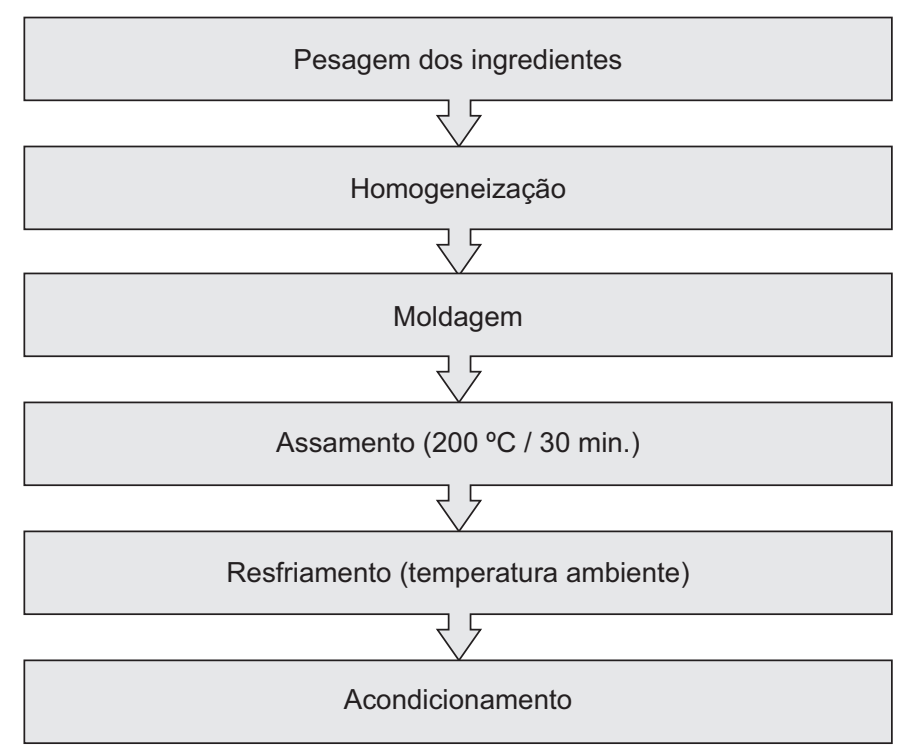

Figura 6.2 Diagrama de blocos do processamento das formulações de biscoitos

Uma vez assados, os biscoitos foram resfriados em temperatura ambiente e acondicionados em recipientes plásticos vedados (Figura 6.3). 


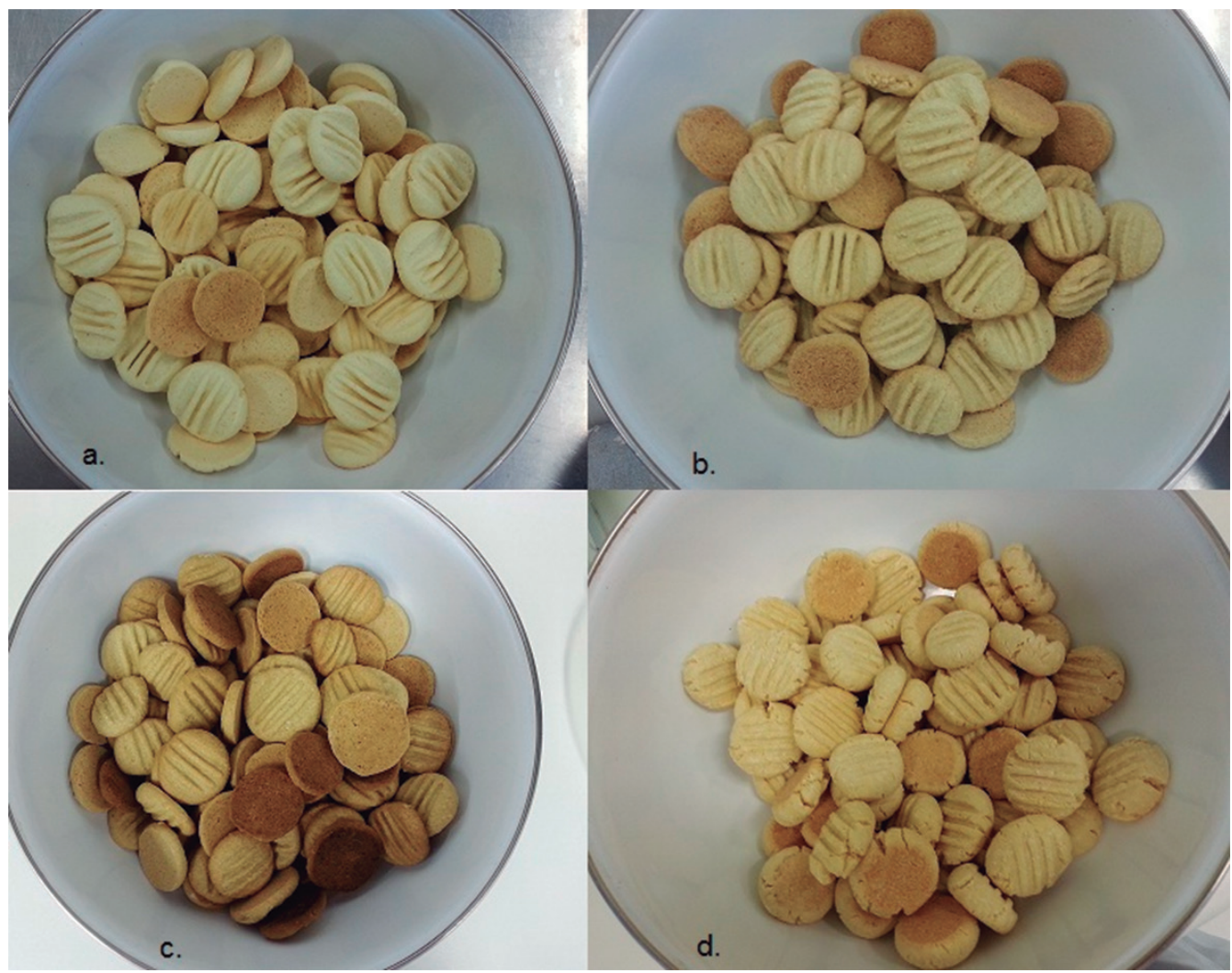

Figura 6.3 Formulações dos biscoitos com as diferentes farinhas: a) trigo; b) quinoa; c) linhaça; d) soja

\subsection{Composição proximal}

As análises da composição proximal foram realizadas em triplicata e seguiram as metodologias descritas pela Association of Analytical Communities (1995). A quantificação de umidade foi realizada em estufa a $105^{\circ} \mathrm{C}$ com circulação de ar, cinzas foram determinadas por carbonização seguida de incineração em mufla a $550{ }^{\circ} \mathrm{C}$, lipídeos foram quantificados por extração em Soxhlet com éter de petróleo, e proteínas foram determinadas calculando o teor de nitrogênio total pelo método Microkjeldahl, usando fator de correção 6,25. Os carboidratos foram calculados por diferença [100-(umidade+cinzas+lipídeos+proteínas)]. As fibras alimentares foram determinadas em duplicata, segundo o método 991.43 da Association of Analytical Communities (1995). As amostras foram previamente desengorduradas (as que apresentaram mais de 10\% de lipídeos) e digeridas enzimaticamente. 


\subsection{Propriedades tecnológicas}

O IAA (índice de absorção de água), IAO (índice de absorção de óleo), densidade e VI (volume de intumescimento) foram determinados em triplicata, segundo Seibel e Beléia (2009). Os IAA e IAO foram quantificados pela suspensão de $1 \mathrm{~g}$ de amostra em $30 \mathrm{ml}$ de água destilada ou óleo em tubos de centrífuga, agitados de forma intermitente durante 30 minutos em agitador horizontal Nova Técnica (NT 155), com velocidade de $150 \mathrm{rpm}$, e centrifugados a $3.000 \mathrm{rpm}$ por 10 minutos (centrífuga Quimis). O sobrenadante foi descartado, e os índices obtidos pela razão entre o peso do sedimento úmido e o peso da matéria seca, expresso em gramas de água/óleo absorvida(o)/grama de matéria seca. A densidade foi determinada diretamente em proveta graduada e balança analítica para medir o peso de $10 \mathrm{ml}$ de amostra. O VI é o volume ocupado pela amostra após duas horas sob agitação magnética e completa decantação, e foi expresso em ml/grama de matéria seca.

\subsection{Determinação de ácidos graxos}

Os ácidos graxos foram analisados em triplicata por CG (cromatografia gasosa), de acordo com Abidi et al. (1999), Bannon et al. (1982), Christie (1989) e Rayford et al. (1994). Alíquotas de $200 \mathrm{mg}$ das amostras foram colocadas em tubos de ensaio com capacidade de $25 \mathrm{ml}$, com $5 \mathrm{ml}$ de solução de metóxido de sódio $\left(\mathrm{NaCH}_{3} \mathrm{OH}\right)$ recém-preparada e homogeneizada em agitador de tubos do tipo vortex (marca Phoenix, modelo AP 56). Depois disso, foram deixadas em repouso por uma hora à temperatura ambiente $\left(24^{\circ} \mathrm{C}\right)$ para que a reação de transesterificação ocorresse; durante esse período, os tubos de ensaio foram agitados. Logo após, foram adicionados, em cada tubo de ensaio, $1 \mathrm{ml}$ de solução aquosa a $10 \%$ de ácido acético glacial e $10 \mathrm{ml}$ de heptano. Foram transferidos para recipientes (vials) próprios para injeção no cromatógrafo gasoso, cerca de 2,0 $\mathrm{ml}$ da camada de heptano.

A análise foi realizada em cromatógrafo a gás da marca Hewlett Packard, modelo 6890, com autoinjetor de amostras, equipado com coluna capilar de sílica de $30 \mathrm{~m}$ de comprimento, 0,32 mm de diâmetro interno e filme com 0,2 $\mu \mathrm{m}$ de espessura da marca Supelco, modelo SP 2340. A análise foi conduzida por cromatografia isotérmica a $190{ }^{\circ} \mathrm{C}$, com um detector de ionização de chama à temperatura de $300{ }^{\circ} \mathrm{C}$ e com temperatura do injetor regulada a $250{ }^{\circ} \mathrm{C}$ durante toda a análise. O fluxo de gases foi regulado para o hélio em $40 \mathrm{ml} / \mathrm{minuto}$, para o hidrogênio em $40 \mathrm{ml} /$ minuto e para o ar sintético em $450 \mathrm{ml} /$ minuto. O volume de injeção foi de 1,0 $\mu \mathrm{L}$ com taxas de split variando de 5:1 a 40:1, dependendo da concentração da amostra. O tempo total de corrida para cada amostra foi de 5 minutos. 


\subsection{Análise sensorial}

Os testes de aceitação foram aplicados em blocos incompletos, em apresentação monádica, com um total de 200 provadores não treinados de ambos os sexos que consentiram em participar da pesquisa e assinaram o termo de consentimento livre e esclarecido. Foi utilizada uma escala hedônica de 10 pontos proposta por Villanueva, Petenate e da Silva (2005), em relação à cor, sabor, textura e aceitação global. Para a aceitação global, foi avaliado o IA (índice de aceitabilidade) proposto por Dutcosky (1996), no qual um produto é considerado aceito quando atinge IA de, no mínimo, 70\%. Esse índice foi calculado a partir da equação $\mathrm{IA}(\%)=\mathrm{A} \times 100 / \mathrm{B}$, no qual $\mathrm{A}=$ nota média obtida para o produto e $\mathrm{B}=$ nota máxima dada ao produto. Para cada formulação também foi realizado um teste de intenção de compra de 5 pontos, onde 5 equivale a "certamente compraria" e 1 equivale a "certamente não compraria".

Dos 200 julgadores que participaram da pesquisa, a maioria era mulheres $(69,5 \%)$, entre vinte e trinta anos (52\%), com ensino médio completo $(66,5 \%)$, que consomem biscoitos doces semanalmente $(48,5 \%)$ e que já ouviram falar em alimentos funcionais $(67,5 \%)$.

\subsection{Tratamento estatístico}

Os dados da composição proximal, das propriedades tecnológicas, dos ácidos graxos e da análise sensorial foram analisados pelo software Statistica 10.0, utilizando análise de variância (Anova), e a diferença entre as médias foi comparada pelo teste de Tukey ao nível de $5 \%$ de significância.

\section{RESULTADOS E DISCUSSÃO}

Comparando as farinhas pelos dados da composição proximal (Tabela 6.2), nota-se que houve diferença significativa entre as farinhas para todos os parâmetros avaliados. A farinha de soja apresentou maiores teores de proteínas $(36,20 \mathrm{~g} / 100$ g), umidade $(11,96 \mathrm{~g} / 100 \mathrm{~g})$ e cinzas $(4,54 \mathrm{~g} / 100 \mathrm{~g})$, indicando apresentar maior conteúdo de minerais. A farinha de linhaça destacou-se das demais por apresentar maior conteúdo lipídico $(45,07 \mathrm{~g} / 100 \mathrm{~g})$, e a de trigo, por apresentar maior média de carboidratos (77,47 g/100 g), seguida pela de quinoa (69,00 g/100 g).

A portaria n. 354 da Anvisa (Agência Nacional de Vigilância Sanitária) prevê que a farinha de trigo deve apresentar no máximo $15 \mathrm{~g} / 100 \mathrm{~g}$ de umidade e 1,35 g/100 g de cinzas, e, no mínimo, 7 g/100 g de proteínas, o que permite afirmar que a amostra analisada está dentro das especificações exigidas pela legislação (BRASIL, 1996). Borges et al. (2003), caracterizando farinha integral de quinoa, encontraram teor de cinzas $(2,39 \mathrm{~g} / 100 \mathrm{~g})$ semelhante e maiores médias para pro- 
teínas $(17,37 \mathrm{~g} / 100 \mathrm{~g})$ e carboidratos $(71,81 \mathrm{~g} / 100 \mathrm{~g})$ em comparação à farinha de quinoa desta pesquisa.

Tabela 6.2 Composição proximal das farinhas $(\mathrm{g} / 100 \mathrm{~g})$

\begin{tabular}{cccccc}
\hline Farinhas & Umidade & Cinzas & Lipideos & Proteinas & Carboidratos \\
\hline Trigo & $11,25 \pm 0,23^{\mathrm{b}}$ & $0,44 \pm 0,28^{\mathrm{d}}$ & $0,23 \pm 0,28^{\mathrm{d}}$ & $10,61 \pm 0,40^{\mathrm{d}}$ & 77,47 \\
Quinoa & $9,78 \pm 0,15^{\mathrm{c}}$ & $2,48 \pm 0,06^{\mathrm{c}}$ & $4,95 \pm 0,68^{\mathrm{c}}$ & $13,79 \pm 0,08^{\mathrm{c}}$ & 69,00 \\
Linhaça & $6,00 \pm 0,19^{\mathrm{d}}$ & $3,54 \pm 0,01^{\mathrm{b}}$ & $45,07 \pm 0,41^{\mathrm{a}}$ & $20,76 \pm 0,81^{\mathrm{b}}$ & 24,63 \\
dourada & & & & & \\
Soja & $11,96 \pm 0,17^{\mathrm{a}}$ & $4,54 \pm 0,06^{\mathrm{a}}$ & $17,84 \pm 0,48^{\mathrm{b}}$ & $36,20 \pm 0,94^{\mathrm{a}}$ & 29,46 \\
\hline
\end{tabular}

Média \pm desvio padrão; médias seguidas pela mesma letra na mesma coluna não apresentam diferença significativa pelo teste de Tukey $(p \leq 0,05)$.

As médias de proteínas e lipídeos da farinha de soja foram inferiores às médias determinadas por Wang et al. (2006) (42,04 g/100 g e 18,63 g/100 g) para farinha integral de soja, porém, a média de cinzas foi próxima $(4,60 \mathrm{~g} / 100 \mathrm{~g})$, e a de carboidratos, superior $(24,48 \mathrm{~g} / 100 \mathrm{~g})$. A composição proximal da farinha de linhaça dourada se diferencia da analisada por Bombo (2006) para torta de linhaça (resíduo obtido após extração do óleo por prensagem a frio), que encontrou médias de 7,85 g/100 g para umidade, 32,81 g/100 g de proteínas, 9 g/100 g de lipídeos e 5,56 g/100 g de cinzas. Essa diferença se deve justamente à diferença do produto analisado.

Segundo Anjo (2004), os efeitos do uso das fibras são a redução dos níveis de colesterol sanguíneo e diminuição dos riscos de desenvolvimento de câncer, decorrentes de três fatores: capacidade de retenção de substâncias tóxicas ingeridas ou produzidas no trato gastrointestinal durante processos digestivos, redução do tempo do trânsito intestinal, promovendo uma rápida eliminação do bolo fecal, com redução do tempo de contato do tecido intestinal com substâncias mutagênicas e carcinogênicas e formação de substâncias protetoras pela fermentação bacteriana dos compostos de alimentação. Nesta pesquisa, a farinha de linhaça foi a que apresentou maior conteúdo de fibras totais, solúveis e insolúveis (Tabela 6.3).

Tabela 6.3 Fibras alimentares das farinhas $(\mathrm{g} / 100 \mathrm{~g})$

\begin{tabular}{cccc}
\hline Farinhas & Fibras solúveis & Fibras insolúveis & Fibras totais \\
\hline Trigo & $0,92 \pm 0,90^{\mathrm{b}}$ & $5,83 \pm 0,25^{\mathrm{d}}$ & $6,51 \pm 0,64^{\mathrm{c}}$ \\
Quinoa & $1,89 \pm 0,75^{\mathrm{b}}$ & $13,77 \pm 0,26^{\mathrm{c}}$ & $10,71 \pm 0,49^{\mathrm{b}}$ \\
Linhaça dourada & $8,85 \pm 1,30^{\mathrm{a}}$ & $41,87 \pm 1,13^{\mathrm{a}}$ & $50,72 \pm 0,17^{\mathrm{a}}$ \\
Soja & $1,11 \pm 1,36^{\mathrm{b}}$ & $17,69 \pm 0,06^{\mathrm{b}}$ & $18,80 \pm 1,30^{\mathrm{b}}$ \\
\hline
\end{tabular}

Média \pm desvio padrão; médias seguidas pela mesma letra na mesma coluna não apresentam diferença significativa pelo teste de Tukey $(p \leq 0,05)$. 
Os teores de fibras totais das farinhas de trigo e quinoa foram superiores aos determinados por Borges et al. (2010), que encontraram média de 2,64 g/100 g para farinha de trigo e 9,59 g/100 g para farinha de quinoa. As médias das farinhas de linhaça e soja também foram significativamente superiores às de outros autores. Wang et al. (2006) encontraram $6,56 \mathrm{~g} / 100 \mathrm{~g}$ de fibra para farinha integral de soja, e Garmus et al. (2009) encontraram 25,24 g/100 g para farinha de linhaça. O consumo de linhaça pode também auxiliar no funcionamento intestinal, graças ao elevado teor de fibra alimentar e de compostos bioativos, como lignanas e compostos fenólicos, que fazem da linhaça um alimento funcional (RIBEIRO, 2012).

As propriedades tecnológicas dos alimentos afetam as características nutritivas e sensoriais dos produtos, além de ter um importante papel físico na preparação, processamento ou estocagem dos alimentos, uma vez que estão relacionadas com a capacidade de hidratação, propriedades relacionadas a tamanho, forma e propriedades de superfície das moléculas (SEIBEL; BELÉIA, 2009). O resultado das análises tecnológicas (Tabela 6.4) permite afirmar que a farinha de linhaça é a que tem maior capacidade de hidratação, pois apresentou 7,31 g/g de IAA e 6,47 $\mathrm{ml} / \mathrm{g}$ de VI, embora esse último índice tenha se aproximado ao da farinha de soja $(6,86 \mathrm{ml} / \mathrm{g})$. Esses índices dependem da conformação molecular, tamanho das partículas e números de sítios de ligação das moléculas (BARBOSA et al., 2011), mas como o tamanho das partículas foi uniformizado, o fato pode estar atribuído ao seu alto teor de fibras. No que diz respeito ao IAO, todas as farinhas apresentaram comportamento semelhante, e, em relação à densidade, as farinhas de linhaça e soja apresentaram os menores valores $(0,29 \mathrm{~g} / \mathrm{ml}$ e $0,33 \mathrm{~g} / \mathrm{ml})$.

Tabela 6.4 Propriedades tecnológicas das farinhas

\begin{tabular}{ccccc}
\hline Farinhas & VI $(\mathbf{m l} / \mathbf{g})$ & IAA $(\mathbf{g} / \mathbf{g})$ & IAO $(\mathbf{g} / \mathbf{g})$ & Densidade $(\mathbf{g} / \mathbf{m l})$ \\
\hline Trigo & $3,14 \pm 0,34^{\mathrm{b}}$ & $2,22 \pm 0,10^{\mathrm{c}}$ & $2,73 \pm 0,16^{\mathrm{a}}$ & $0,50 \pm 0,01^{\mathrm{b}}$ \\
Quinoa & $2,55 \pm 0,34^{\mathrm{b}}$ & $2,88 \pm 0,19^{\mathrm{bc}}$ & $2,92 \pm 0,26^{\mathrm{a}}$ & $0,56 \pm 0,02^{\mathrm{a}}$ \\
Linhaça dourada & $6,47 \pm 0,59^{\mathrm{a}}$ & $7,31 \pm 1,03^{\mathrm{a}}$ & $2,56 \pm 0,23^{\mathrm{a}}$ & $0,29 \pm 0,01^{\mathrm{c}}$ \\
Soja & $6,86 \pm 0,34^{\mathrm{a}}$ & $3,82 \pm 0,39^{\mathrm{b}}$ & $3,04 \pm 0,29^{\mathrm{a}}$ & $0,33 \pm 0,03^{\mathrm{c}}$ \\
\hline
\end{tabular}

Média \pm desvio padrão; $\mathrm{VI}$ = volume de intumescimento; IAA = índice de absorção de água; $I A O=$ índice de absorção de óleo. Médias seguidas pela mesma letra na mesma coluna não apresentam diferença significativa pelo teste de Tukey $(p \leq 0,05)$.

Barbosa et al. (2011) analisaram farinha de okara e encontraram valor de $3,81 \mathrm{~g} / \mathrm{g}$ de IAO, o que se aproxima da média analisada neste estudo para todas as farinhas, sugerindo que todas possuem a mesma disponibilidade de grupos lipofílicos. Esses mesmos autores encontraram média significativamente superior $(8,63 \mathrm{~g} / \mathrm{g})$ de VI ao encontrado para as farinhas de trigo, quinoa, linhaça dourada e soja desta pesquisa. 
Quanto à densidade, a média da farinha de quinoa foi próxima da média reportada $(0,58 \mathrm{~g} / \mathrm{ml})$ por Akubor e Ukwuru (2003) para farinha de soja. As demais médias analisadas nesta pesquisa foram inferiores à média encontrada por esses autores para farinha de mandioca $(0,63 \mathrm{~g} / \mathrm{ml})$. Silva et al. (2011) atribuíram diferenças na densidade de farinhas devido à inexistência de padronização na produção, mas, como neste trabalho as farinhas foram produzidas sob as mesmas condições, a diferença na densidade está atribuída somente às alterações nas estruturas físicas das matrizes dos diferentes grãos utilizados.

Houve diferença significativa quanto ao total dos ácidos graxos (Tabela 6.5) nas diferentes farinhas utilizadas, sendo a farinha de linhaça a que apresentou maior teor $(28,22 \mathrm{~g} / 100 \mathrm{~g})$. Os ácidos graxos são classificados conforme a presença de duplas ligações (insaturações) entre as cadeias de carbono. São denominados ácidos graxos saturados na ausência de duplas ligações; ácidos graxos monoinsaturados pela presença de uma insaturação; ácidos graxos poli-insaturados pela presença de duas ou mais insaturações (YOUDIM; MARTIN; JOSEPH, 2000 apud PERINI et al., 2010).

Tabela 6.5 Teor dos ácidos graxos das farinhas $(\mathrm{g} / 100 \mathrm{~g})$

\begin{tabular}{ccccc}
\hline & Trigo & Quinoa & Linhaça dourada & Soja \\
\hline Palmítico (16:0) & $0,14 \pm 0,01^{\mathrm{c}}$ & $0,32 \pm 0,01^{\mathrm{b}}$ & $1,52 \pm 0,02^{\mathrm{a}}$ & $1,51 \pm 0,06^{\mathrm{a}}$ \\
Esteárico (18:0) & - & - & $1,07 \pm 0,02^{\mathrm{a}}$ & $0,35 \pm 0,01^{\mathrm{b}}$ \\
$\quad$ Araquídico & - & - & - & $0,04 \pm 0,01^{\mathrm{a}}$ \\
$\quad(20: 0)$ & & & & \\
Oleico (18:1) & $0,17 \pm 0,06^{\mathrm{d}}$ & $0,78 \pm 0,04^{\mathrm{c}}$ & $6,19 \pm 0,11^{\mathrm{a}}$ & $5,05 \pm 0,16^{\mathrm{b}}$ \\
Linoleico (18:2) & $0,53 \pm 0,03^{\mathrm{d}}$ & $1,62 \pm 0,06^{\mathrm{c}}$ & $4,87 \pm 0,09^{\mathrm{b}}$ & $6,24 \pm 0,20^{\mathrm{a}}$ \\
Linolênico (18:3) & - & $0,26 \pm 0,01^{\mathrm{b}}$ & $14,57 \pm 0,90^{\mathrm{a}}$ & $0,75 \pm 0,02^{\mathrm{b}}$ \\
Total & $0,83 \pm 0,09^{\mathrm{d}}$ & $2,98 \pm 0,12^{\mathrm{c}}$ & $28,22 \pm 0,77^{\mathrm{a}}$ & $13,95 \pm 0,45^{\mathrm{b}}$ \\
\hline
\end{tabular}

Média \pm desvio padrão; médias seguidas pela mesma letra na mesma linha não apresentam diferença significativa pelo teste de Tukey $(\mathrm{p} \leq 0,05)$.

Os ácidos graxos saturados se apresentam na forma sólida à temperatura ambiente, e podem ser de cadeias médias ou longas. Dentre os de cadeias longas, os que mais se destacam são o palmítico, esteárico e araquídico. O ácido palmítico e o araquídico tendem a elevar a concentração plasmática de colesterol e de LDL (lipoproteína de baixa densidade), diferentemente do esteárico, que não eleva a colesterolemia por ser rapidamente convertido a ácido oleico no fígado (LOTTENBERG, 2009).

Com relação ao teor desses ácidos graxos, a farinha de linhaça foi a que apresentou maior média do esteárico $(1,07 \mathrm{~g} / 100 \mathrm{~g})$ e, junto com a farinha de 
soja, a maior média do palmítico (1,52 g/100 g e 1,51 g/100 g, respectivamente). Apesar de insignificante, a farinha de soja foi a única que apresentou perfil de araquídico $(0,04 \mathrm{~g} / 100 \mathrm{~g})$. As farinhas de trigo e quinoa também não apresentaram conteúdo de esteárico, e obtiveram pequenos índices de palmítico, 0,14 g/100 g e $0,32 \mathrm{~g} / 100 \mathrm{~g}$, respectivamente.

Quanto aos ácidos graxos insaturados, sua classificação se baseia no número de duplas ligações, podendo ser denominados mono ou poli-insaturados, pertencendo a diferentes séries, definidas pela localização da primeira dupla ligação na cadeia de carbono a partir do terminal metila, identificada pela letra $\omega$. Dessa forma, esses ácidos graxos são classificados em série $\omega-3, \omega-6$ e $\omega-9$. O ácido oleico, da série $\omega-9$, é o ácido graxo monoinsaturado mais frequentemente encontrado na natureza, e o poliinsaturado mais abundante é o linoleico pertencente à série $\omega$-6. O linolênico, da série $\omega$-3, é frequentemente encontrado na linhaça, soja e canola (LOTTENBERG, 2009).

Os resultados mostraram que a farinha de linhaça foi a que apresentou maior teor de linolênico $(14,57 \mathrm{~g} / 100 \mathrm{~g})$ e oleico $(6,19 \mathrm{~g} / 100 \mathrm{~g})$, e a farinha de soja, maior conteúdo de linoleico $(6,24 \mathrm{~g} / 100 \mathrm{~g})$. A farinha de trigo não apresentou perfil significativo de linolênico e apresentou os menores teores de oleico $(0,17 \mathrm{~g} / 100 \mathrm{~g})$ e linoleico $(0,53 \mathrm{~g} / 100 \mathrm{~g})$. A literatura relata que o consumo desse tipo de ácidos graxos pode reduzir os teores de LDL e que a substituição de gordura saturada por poli-insaturada reduz o risco cardiovascular (LOTTENBERG, 2009); com isso, conclui-se que a farinha com melhor perfil lipídico é a farinha de linhaça.

Este estudo confirma a pesquisa de Morris (2001), que diz que a linhaça possui alto índice de ácidos graxos poli-insaturados, moderado em ácidos graxos monoinsaturados e baixo em ácidos graxos saturados, e a pesquisa de Repo-Carrasco-Valencia e Serna (2011), que menciona que a farinha de quinoa apresenta maior concentração de ácido linoleico, seguido de oleico (MORRIS, 2001 apud LIMA, 2007).

Estudos mostram que a utilização de farinhas de oleaginosas em produtos de panificação tem melhorado a qualidade nutricional desses tipos de produtos. Analisando a composição proximal (Tabela 6.6) das formulações dos biscoitos, nota-se que a adição das farinhas de linhaça dourada e de soja reduziu o teor de carboidratos (de 74,11 g/100 g para 63,04 g/100 g e 62,50 g/100 g) e aumentou o conteúdo de cinzas (de 0,85 g/100 g para 1,44 g/100 g e 1,55 g/100 g) e proteínas (de 4,97 g/100 g para 6,28 g/100 g e 8,69 g/100 g), confirmando a melhoria na qualidade nutricional dos produtos enriquecidos com estas farinhas.

A TACO (Tabela Brasileira de Composição de Alimentos) (UNIVERSIDADE ESTADUAL DE CAMPINAS, 2006) estabelece para biscoito que contenha em sua formulação polvilho doce 5,4 g/100 g de umidade, 1,3 g/100 g de proteínas, 12,2 g/100 g de lipídeos, 80,5 g/100 g de carboidratos e 0,5 g/100 g de cinzas. 
Tendo como base esses valores, nota-se que a amostra padrão apresentou maiores teores de proteínas, lipídeos e cinzas, o que pode ser consequência dos demais ingredientes utilizados na formulação.

Tabela 6.6 Composição proximal dos biscoitos $(\mathrm{g} / 100 \mathrm{~g})$

\begin{tabular}{cccccc}
\hline Biscoitos & Umidade & Cinzas & Lipídeos & Proteínas & Carboidratos \\
\hline Trigo & $3,51 \pm 0,23^{\mathrm{b}}$ & $0,85 \pm 0,01^{\mathrm{b}}$ & $16,56 \pm 1,01^{\mathrm{b}}$ & $4,97 \pm 0,89^{\mathrm{c}}$ & 74,11 \\
Quinoa & $2,89 \pm 0,28^{\mathrm{c}}$ & $1,10 \pm 0,19^{\mathrm{b}}$ & $17,57 \pm 1,19^{\mathrm{b}}$ & $4,36 \pm 0,85^{\mathrm{c}}$ & 74,08 \\
Linhaça dourada & $3,21 \pm 0,09^{\mathrm{bc}}$ & $1,44 \pm 0,09^{\mathrm{a}}$ & $26,03 \pm 0,33^{\mathrm{a}}$ & $6,28 \pm 0,09^{\mathrm{b}}$ & 63,04 \\
Soja & $9,20 \pm 0,04^{\mathrm{a}}$ & $1,55 \pm 0,04^{\mathrm{a}}$ & $17,97 \pm 0,47^{\mathrm{b}}$ & $8,69 \pm 0,73^{\mathrm{a}}$ & 62,59 \\
\hline
\end{tabular}

Média \pm desvio padrão; médias seguidas pela mesma letra na mesma coluna não apresentam diferença significativa pelo teste de Tukey $(p \leq 0,05)$.

As médias obtidas para umidade e cinzas da amostra com farinha de quinoa foram superiores às da composição proximal obtida por Giovanella, Schlabitz e de Souza (2013) para biscoitos elaborados com farinha de quinoa e fécula de batata. Os autores encontraram médias de 2,5 g/100 g de umidade e 1,3 g/100 g de cinzas. As médias reportadas por esses autores para proteínas e carboidratos foram maiores, $5 \mathrm{~g} / 100$ g e 74,8 g/100 g, respectivamente. O teor de lipídeos foi semelhante, 16,3 g/100 g.

A caracterização do biscoito de linhaça se distancia das médias encontradas em biscoitos tipo cracker com $20 \%$ de farinha de linhaça analisadas por Maciel, Pontes e Rodrigues (2008), justamente pela diferença dos ingredientes utilizados na formulação. Os autores utilizaram bicarbonato de sódio e gordura vegetal hidrogenada, encontrando médias de 4,92 g/100 g de umidade, 2,50 g/100 g de cinzas, 25,8 g/100 g de proteínas, 15,82 g/100 g de lipídeos e 41,25 g/100 g de carboidratos.

Utilizando farinha de soja comercial para elaboração dos biscoitos, Santos et al. (2010) encontraram teores de 7,81 g/100 g de proteínas, 18,38 g/100 g de lipídeos e 1,02 g/100 g de cinzas, o que se aproxima dos teores obtidos para lipídeos e proteínas dos biscoitos com farinha de soja analisados nesta pesquisa. O teor de cinzas foi significativamente superior, mas deve-se ao fato de a farinha utilizada ser integral.

Os dados do conteúdo de fibras alimentares das formulações dos biscoitos (Tabela 6.7) permitem afirmar que a utilização das diferentes farinhas incrementou o teor de fibras totais, sendo que a utilização das farinhas de linhaça e de soja apresentaram os melhores resultados (12,02 g/100 g e 10,92 g/100 g, respectivamente). Mesmo assim, de acordo com a legislação vigente, todas as formulações adicionadas das diferentes farinhas de oleaginosas são consideradas fonte de fibras, pois a Portaria n. 27, de 13/01/1998, da Anvisa (BRASIL, 1998) prevê que 
um alimento é fonte de fibras alimentares quando apresenta, no mínimo, $3 \%$ de fibras e possui alto teor de fibras quando apresenta, no mínimo, $6 \%$.

Tabela 6.7 Fibras alimentares dos biscoitos $(\mathrm{g} / 100 \mathrm{~g})$

\begin{tabular}{cccc}
\hline Biscoitos & Fibras solúveis & Fibras insolúveis & Fibras totais \\
\hline Trigo & $0,82 \pm 0,13^{b}$ & $1,21 \pm 0,42^{c}$ & $2,03 \pm 0,30^{c}$ \\
Quinoa & $1,21 \pm 0,02^{a b}$ & $5,30 \pm 0,07^{b}$ & $6,51 \pm 0,10^{b}$ \\
Linhaça dourada & $2,20 \pm 0,48^{a}$ & $9,82 \pm 0,14^{a}$ & $12,02 \pm 0,61^{a}$ \\
Soja & $0,77 \pm 0,02^{b}$ & $10,15 \pm 0,09^{a}$ & $10,92 \pm 0,07^{a}$ \\
\hline
\end{tabular}

Média \pm desvio padrão; médias seguidas pela mesma letra na mesma coluna não apresentam diferença significativa pelo teste de Tukey $(p \leq 0,05)$.

Segundo a TACO (UNIVERSIDADE ESTADUAL DE CAMPINAS, 2006), o teor médio de fibras para biscoito com polvilho doce é de $1,2 \mathrm{~g} / 100 \mathrm{~g}$, o que está abaixo do valor determinado neste estudo, fato que pode estar atribuído à presença de coco ralado na formulação, que apresenta média de 9,4 g/100 g de fibras totais (BRASIL, 2005). O teor de fibras do biscoito com farinha de quinoa foi próximo ao valor quantificado por Giovanella, Schlabitz e de Souza (2013), que encontraram média de 6,75 g/100 g para biscoito com farinha de quinoa e fécula de batata.

A média de fibras totais para o biscoito com farinha de linhaça também foi próxima à quantidade determinada por Maciel, Pontes e Rodrigues (2008) (12,22 $\mathrm{g} / 100 \mathrm{~g}$ ) para biscoito tipo cracker com $20 \%$ de farinha de linhaça. E, apesar de a porcentagem de farinha de soja utilizada ter sido parecida, o teor de fibras totais do biscoito de soja foi significativamente superior à média encontrada por Vasconcelos et al. (2006) (5,96 g/100 g) para pão de forma com $15 \%$ de farinha de soja.

Os dados das propriedades tecnológicas dos biscoitos (Tabela 6.8) mostraram que a única diferença foi quanto ao IAA, cuja formulação com farinha de linhaça apresentou maior média $(2,36 \mathrm{~g} / \mathrm{g})$, confirmando a maior capacidade de hidratação dessa farinha, que pode ser notada na maior maleabilidade da massa.

Tabela 6.8 Propriedades tecnológicas dos biscoitos

\begin{tabular}{ccccc}
\hline Biscoitos & VI $(\mathbf{m l} / \mathbf{g})$ & IAA $(\mathrm{g} / \mathrm{g})$ & IAO $(\mathrm{g} / \mathrm{g})$ & Densidade $(\mathrm{g} / \mathrm{ml})$ \\
\hline Trigo & $2,75 \pm 0,34^{\mathrm{a}}$ & $2,12 \pm 0,09^{\mathrm{b}}$ & $2,44 \pm 0,28^{\mathrm{a}}$ & $0,45 \pm 0,03^{\mathrm{a}}$ \\
Quinoa & $2,55 \pm 0,34^{\mathrm{a}}$ & $2,08 \pm 0,05^{\mathrm{b}}$ & $2,15 \pm 0,38^{\mathrm{a}}$ & $0,47 \pm 0,03^{\mathrm{a}}$ \\
Linhaça dourada & $3,53 \pm 0,59^{\mathrm{a}}$ & $2,36 \pm 0,06^{\mathrm{a}}$ & $2,02 \pm 0,04^{\mathrm{a}}$ & $0,41 \pm 0,03^{\mathrm{a}}$ \\
Soja & $2,55 \pm 0,34^{\mathrm{a}}$ & $1,99 \pm 0,04^{\mathrm{b}}$ & $2,62 \pm 0,15^{\mathrm{a}}$ & $0,43 \pm 0,01^{\mathrm{a}}$ \\
\hline
\end{tabular}

Média \pm desvio padrão; $\mathrm{VI}$ = volume de intumescimento; $I \mathrm{AA}=$ índice de absorção de água; $I \mathrm{AO}=$ índice de absorção de óleo. Médias seguidas pela mesma letra na mesma coluna não apresentam diferença significativa pelo teste de Tukey $(p \leq 0,05)$. 
As médias de VI de todas as formulações foram superiores às encontradas em biscoitos mistos com farinha de trigo e farinha de jatobá, $1,53 \mathrm{ml} / \mathrm{g}$ (SILVA et al., 2001), e de biscoitos contendo $20 \%$ de farelo de arroz, $1,36 \mathrm{ml} / \mathrm{g}$ (FEDDERN et al., 2011). Os índices de absorção de água e de óleo foram respectivamente menores e próximos aos determinados por de Ávila et al. (2010) em biscoito tipo cookie com fécula de mangarito, que encontraram médias de 4,65 g/g para absorção de água e $2,40 \mathrm{~g} / \mathrm{g}$ para absorção de óleo. O alto valor de IAA confirma a interação dos grupos hidrofílicos e a capacidade de formar gel das moléculas de amido, pois o mangarito pertence à família das tuberosas amiláceas, nas quais o componente predominante é o amido/fécula. A densidade dos biscoitos se aproximou da encontrada para biscoito cracker adicionado de $20 \%$ de farinha de linhaça $(0,50 \mathrm{~g} / \mathrm{ml})$ (MACIEL; PONTES; RODRIGUES, 2008).

Analisando o conteúdo total de ácidos graxos dos biscoitos (Tabela 6.9), a formulação com farinha de linhaça apresentou maior quantidade (14,74 g/100 g) e também o maior teor de linolênico (3,85 g100 g). Quanto aos demais ácidos graxos, todas as formulações apresentaram conteúdos próximos.

Tabela 6.9 Teor dos ácidos graxos dos biscoitos $(\mathrm{g} / 100 \mathrm{~g})$

\begin{tabular}{ccccc}
\hline & Trigo & Quinoa & Linhaça dourada & Soja \\
\hline $\begin{array}{c}\text { Palmítico (16:0) } \\
\text { Esteárico }\end{array}$ & $1,85 \pm 0,07^{\mathrm{a}}$ & $1,70 \pm 0,08^{\mathrm{a}}$ & $1,99 \pm 0,24^{\mathrm{a}}$ & $1,74 \pm 0,30^{\mathrm{a}}$ \\
$\quad$ (18:0) & $0,84 \pm 0,03^{\mathrm{ab}}$ & $0,77 \pm 0,05^{\mathrm{b}}$ & $1,00 \pm 0,12^{\mathrm{a}}$ & $0,72 \pm 0,14^{\mathrm{b}}$ \\
$\begin{array}{c}\text { Araquídico } \\
\text { (20:0) }\end{array}$ & $0,04 \pm 0,01^{\mathrm{a}}$ & $0,04 \pm 0,01^{\mathrm{a}}$ & $0,04 \pm 0,01^{\mathrm{a}}$ & $0,03 \pm 0,02^{\mathrm{a}}$ \\
Oleico (18:1) & $3,45 \pm 0,09^{\mathrm{b}}$ & $3,27 \pm 0,28^{\mathrm{b}}$ & $4,51 \pm 0,53^{\mathrm{a}}$ & $3,62 \pm 0,70^{\mathrm{ab}}$ \\
$\begin{array}{c}\text { Linoleico (18:2) } \\
\text { Linolênico }\end{array}$ & $2,61 \pm 0,06^{\mathrm{a}}$ & $2,63 \pm 0,20^{\mathrm{a}}$ & $3,35 \pm 0,40^{\mathrm{a}}$ & $3,17 \pm 0,59^{\mathrm{a}}$ \\
$\quad$ (18:3) & $0,24 \pm 0,01^{\mathrm{b}}$ & $0,26 \pm 0,02^{\mathrm{b}}$ & $3,85 \pm 0,45^{\mathrm{a}}$ & $0,33 \pm 0,06^{\mathrm{b}}$ \\
Total & $9,04 \pm 0,26^{\mathrm{b}}$ & $8,68 \pm 0,63^{\mathrm{b}}$ & $14,74 \pm 1,74^{\mathrm{a}}$ & $9,61 \pm 1,81^{\mathrm{b}}$ \\
\hline
\end{tabular}

Média \pm desvio padrão; médias seguidas pela mesma letra na mesma linha não apresentam diferença significativa pelo teste de Tukey $(\mathrm{p} \leq 0,05)$.

Chiara, Sichieri e Carvalho (2003) analisaram o perfil de ácidos graxos de biscoitos tipo cream cracker e, assim como neste estudo, não verificaram a presença de ácidos graxos saturados de cadeia curta, pois esses são característicos de gordura láctea, enquanto o teor de oleico $(3,43 \mathrm{~g} / 100 \mathrm{~g})$ foi semelhante aos das formulações de trigo, quinoa e soja. $\mathrm{O}$ teor de linoleico encontrado por esses autores $(0,90 \mathrm{~g} / 100$ g) ficou bem abaixo dos encontrados para todas as amostras desta pesquisa, pois 0 
ácido linoleico é proveniente de nozes, grãos e sementes, e os biscoitos tipo cream cracker não utilizam esses ingredientes em sua formulação.

Os teores de esteárico e araquídico foram maiores e próximos aos determinados por Bottan (2010), que analisou biscoito doce simples e encontrou valores de $0,64 \mathrm{~g} / 100 \mathrm{~g}$ e $0,04 \mathrm{~g} / 100 \mathrm{~g}$, respectivamente. Porém, os teores de palmítico (40 g/100 g) e oleico $(39,2 \mathrm{~g} / 100 \mathrm{~g})$ analisados por esse autor foram bem superiores a todas as formulações, e o teor de linolênico, $(0,06 \mathrm{~g} / 100 \mathrm{~g})$, significativamente inferior.

Em relação aos dados da análise sensorial (Tabela 6.10), nota-se que as maiores médias para cor foram para as formulações com farinha de trigo $(8,60)$ e linhaça $(8,15)$, e essas não diferiram significativamente das demais formulações, sugerindo que as diferentes farinhas se comportaram de forma semelhante durante o processamento e que o tempo de assamento foi adequado. Entretanto, com relação ao sabor e aceitação global, houve diferença entre as amostras, sendo que a formulação com farinha de trigo alcançou os melhores índices (9,04 e 9,09, respectivamente). Para textura, o biscoito com farinha de soja obteve a menor nota $(6,90)$, fato que pode ser devido à menor crocância apresentada por essa amostra.

Tabela 6.10 Análise sensorial de aceitação das formulações de biscoito

\begin{tabular}{ccccc}
\hline Biscoitos & Cor & Sabor & Textura & Aceitação global \\
\hline Trigo & $8,60 \pm 1,20^{a}$ & $9,04 \pm 1,23^{\mathrm{a}}$ & $9,05 \pm 0,99^{\mathrm{a}}$ & $9,09 \pm 1,04^{\mathrm{a}}$ \\
Quinoa & $7,58 \pm 1,86^{\mathrm{b}}$ & $7,71 \pm 1,55^{\mathrm{b}}$ & $8,47 \pm 1,35^{\mathrm{ab}}$ & $7,91 \pm 1,38^{\mathrm{b}}$ \\
Linhaça dourada & $8,15 \pm 1,49^{\mathrm{ab}}$ & $8,16 \pm 1,51^{\mathrm{b}}$ & $8,01 \pm 1,74^{\mathrm{b}}$ & $7,93 \pm 1,70^{\mathrm{b}}$ \\
Soja & $7,70 \pm 1,82^{\mathrm{b}}$ & $7,75 \pm 1,98^{\mathrm{b}}$ & $6,90 \pm 2,25^{\mathrm{c}}$ & $7,53 \pm 1,81^{\mathrm{b}}$ \\
\hline
\end{tabular}

Média \pm desvio padrão; médias seguidas pela mesma letra na mesma coluna não apresentam diferença significativa pelo teste de Tukey $(p \leq 0,05)$. Escala hedônica de dez pontos $(0=$ desgostei extremamente e 10 = gostei extremamente).

O índice de aceitabilidade (IA) da impressão global das formulações de trigo, quinoa, linhaça dourada e soja foram $90,9 \%, 79,1 \%, 79,3 \%$ e $75,3 \%$, respectivamente, e, com isso, concluiu-se que todas as amostras foram bem aceitas, pois, segundo Dutcosky (1996), um produto é considerado aceito quando atinge IA de no mínimo $70 \%$.

As médias obtidas para a formulação com farinha de quinoa superam as médias relatadas por Giovanella, Schlabitz e de Souza (2013) para biscoitos elaborados com farinha de quinoa e fécula de batata, que foram 7,29 para aparência, 6,46 para sabor, 7,23 para textura e 7,20 para impressão global. A formulação com farinha de linhaça obteve superioridade quanto aos atributos sabor $(6,18)$, 
textura $(6,7)$ e aceitação geral $(6,37)$ obtidos para pão com $10 \%$ de farinha de linhaça e $3 \%$ de farinha de maracujá (LIMA, 2007).

Os biscoitos elaborados com farinha de soja também apresentaram médias superiores às reportadas por Vasconcelos et al. (2006) em um teste de aceitação de pão de forma com $15 \%$ de farinha de soja. Os autores encontraram apenas 6,15 para sabor, 7,12 para aparência e 6,50 para aceitação global.

Esses valores confirmaram a aceitabilidade de todas as formulações. E, apesar de a formulação de trigo ter apresentado melhor aceitação $(66 \%$ "certamente comprariam") (Figura 6.4), todas as formulações obtiveram médias entre "provavelmente" e "certamente compraria", e nenhuma recebeu intenções de "certamente não compraria". As formulações com farinha de quinoa, de linhaça e de soja obtiveram respectivamente médias de 74\%, 78\% e 70\% para "certamente" e "provavelmente compraria", e apenas $2 \%, 6 \%$ e $6 \%$ de "provavelmente não compraria".

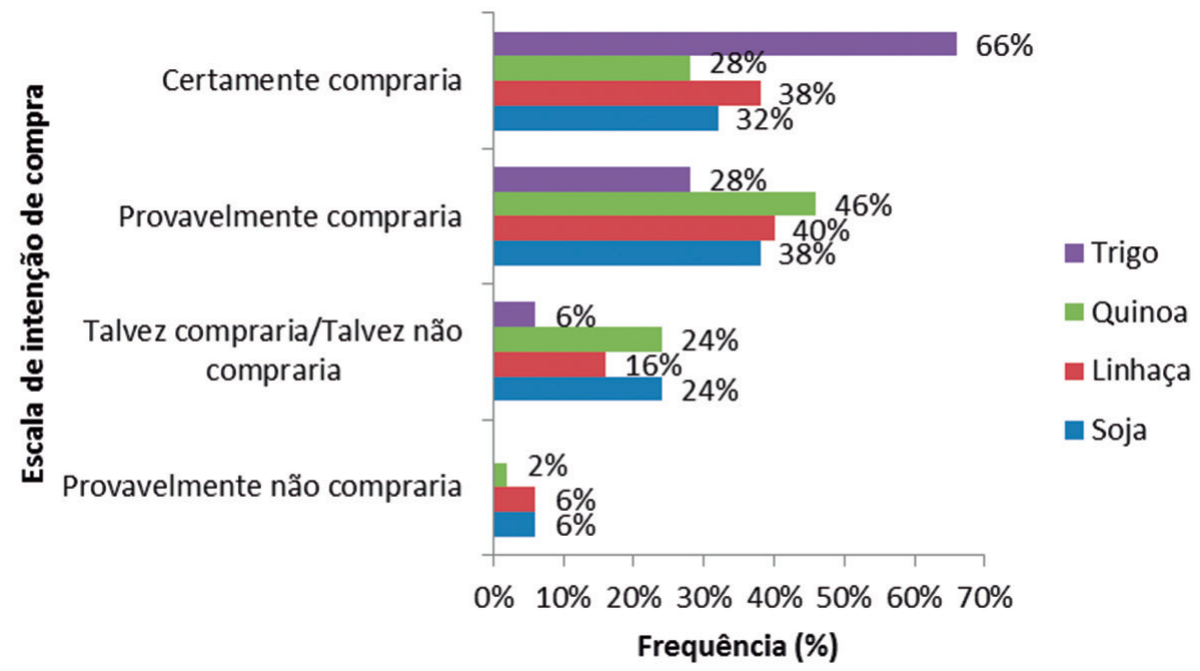

Figura 6.4 Intenção de compra das diferentes formulações de biscoitos

As médias de intenção de compra das formulações testadas neste experimento foram superiores às encontradas por Giovanella, Schlabitz e de Souza (2013) quando avaliaram a intenção de compra de biscoitos elaborados com farinha de quinoa e fécula de batata, e por Vasconcelos et al. (2006) para pão de forma com $15 \%$ de farinha de soja. As médias foram de $50 \%$ a $62,5 \%$ de menções positivas para o biscoito, e de apenas $10 \%$ "certamente compraria" para o pão de forma.

\section{CONCLUSÃO}

Por meio da pesquisa, foi possível a elaboração dos biscoitos doces sabor coco com as diferentes farinhas utilizadas, sendo que o uso das farinhas de soja e de linha- 
ça mostraram os melhores índices nutricionais. As formulações com essas farinhas obtiveram aumento significativo no teor de proteínas e cinzas, além de redução no teor de carboidratos. As formulações tiveram suas qualidades nutritivas melhoradas, sendo consideradas "alimentos com alto teor de fibras". Todas as formulações foram bem aceitas por parte dos julgadores e alcançaram médias desejáveis quanto à intenção de compra. Consequentemente, os biscoitos mostraram-se produtos promissores para serem inseridos no mercado, pois foram eficientes veículos para enriquecimento nutricional, além de terem sido bem aceitos sensorialmente.

\section{REFERÊNCIAS}

ABIDI, S. L.; LIST, G. R.; RENNICK, K. A. Effect of genetic modification on the distribuition of minor constituents in canola oil. Journal of American Oil Chemistry Society, v. 76, n. 4, p. 463-467, 1999.

ADITIVOS E INGREDIENTES. Produtos de panificação com benefícios. Disponível em: <http://www.insumos.com.br/aditivos_e_ingredientes/materias/325.pdf $>$. Acesso em: 17 jun. 2013.

AKUBOR, P. I.; UKWURU. M. U. Functional properties and biscuit making potential of soybean and cassava flour blends. Plant Foods for Human Nutrition, Idah, v. 58, n. 3, p. 1-12, 2003.

ANJO, D. L. C. Alimentos funcionais em angiologia e cirurgia vascular. Jornal Vascular Brasileiro, v. 3, n. 2, p. 145-154, 2004.

ASSOCIATION OF ANALYTICAL COMMUNITIES. Official methods of analysis. 16.ed. Arlington: Association of Analytical Communities, 1995. v.1-2.

BANNON, C. D. et al. Journal of Chromatography, v. 247, p. 71, 1982.

BARBOSA, J. R. et al. Avaliação da composição e dos parâmetros tecnológicos de farinhas produzidas a partir de subprodutos agroindustriais. Revista Tecnológica, Edição Especial V Simpósio de Engenharia, Ciência e Tecnologia de Alimentos, p. 21-28, 2011.

BASHO, S. M.; BIN, M. C. Propriedades dos Alimentos Funcionais e Seu Papel Na Prevenção e Controle da Hipertensão e Diabetes. Interbi, Rio de Janeiro, v. 4, n. 1, 2010. BOMBO, A. J. Obtenção e caracterização nutricional de snacks de milho e linhaça. Dissertação (Mestrado em Saúde Pública) - Faculdade de Saúde Pública da Universidade de São Paulo, São Paulo, 2006.

BORGES, J. T. S. et al. Propriedades de cozimento e caracterização físico-química de macarrão pré-cozido à base de farinha integral de quinoa (Chenopodium quinoa, Willd) e de farinha de arroz (Oryza sativa, L) polido por extrusão termoplástica. B.CEPPA, Curitiba, v. 21, n. 2, jul./dez. 2003.

- Características físico-químicas, nutricionais e formas de consumo da quinoa

(Chenopodium quinoa Willd.). Temas Agrários, v. 15, n. 1, p. 9-23, jan./jun. 2010.

- Qualidade nutricional de pão de forma enriquecido com farinha de quinoa. ver. Alimentos Hoy, v. 21, n. 27, p. 55-67, 2012. 
BOTTAN, T. Avaliação do teor de ácidos graxos trans em alimentos comercializados na cidade de São Paulo. 2010. 99 f. Dissertação (Pós-graduação e nutriçã) - Faculdade de Saúde Pública da Universidade Estadual de São Paulo, São Paulo, 2010.

BRASIL. Ministério da Saúde. Resolução n. 12, de 24 de julho de 1978. Normas técnicas relativas a alimentos (e bebidas), para efeito em todo território brasileiro. Diário Oficial da União da República Federativa do Brasil, Brasília, DF, 24 jul. 1978. - Ministério da Saúde. Portaria n³54, de 18 de julho de 1996. Norma Técnica referente a Farinha de Trigo. Diário Oficial da União da República Federativa do Brasil, Brasília, DF, 22 jul. 1996.

- Ministério da Saúde. Resolução n. 18, de 30 de abril de 1999. Regulamento Técnico que estabelece as diretrizes básicas para análise e comprovação de propriedades funcionais e ou de saúde alegadas em rotulagem de alimentos, constante do anexo desta portaria. Diário Oficial da União da República Federativa do Brasil, Brasília, DF, 03 maio 1999.

Ministério da Saúde. Resolução n. 263, de 22 de setembro de 2005.

Regulamento técnico para produtos de cereais, amidos, farinhas e farelos. Diário Oficial da União da República Federativa do Brasil, Brasília, DF, 22 set. 2005.

- Ministério da Saúde. Agência Nacional de Vigilância Sanitária. Rotulagem Nutricional Obrigatória: Manual de Orientação às Indústrias de Alimentos. Brasília, DF, 2005.

- Ministério da Saúde. Agência Nacional de Vigilância Sanitária. Portaria nº 27 de 13 de janeiro de 1998. Regulamento Técnico Referente à Informação Nutricional Complementar. Disponível em: <http://www.anvisa.gov.br/alimentos/legis> Acesso em: 21 set. 2013.

BUENO, M. M. Desenvolvimento e aceitabilidade de pão de forma enriquecido com polidextrose e flocos de quinoa. Dissertação (Graduação em Tecnologia em Alimentos) - Instituto Federal de Educação, Ciência e Tecnologia do Rio Grande do Sul, Bento Golçalves, 2012. $71 \mathrm{f}$.

CABALLERO-CÓRDOBA, G. M.; WANG S.; SGARBIBIERI, V. C. Características nutricionais e sensoriais de sopa cremosa semi-instantânea à base de farinhas de trigo e soja desengordurada. Pesq. Agropec. Bras., Brasília, v. 29, n. 7, p. 1137-1143, jul. 1994. CALDERELLI, V. A. S. et al. Quinoa e linhaça: ingredientes potenciais na produção de pão com qualidade funcional. Braz. Arco. Biol. Tecnologia, Curitiba, v. 53, n. 4, jul./ago. 2010.

CÂNDIDO, L. M. B.; CAMPOS, A. M. Alimentos funcionais. Uma revisão. Boletim da SBCTA, v. 29, n. 2, p. 193-203, 2005.

CARDOSO, A. L.; OLIVEIRA, G. G. Alimentos funcionais. UFSC, 2008. Disponível em: <http://www.nutrijr.ufsc.br/jornal/jornal_eletronico_06-08.pdf>. Acesso em: 12 jun. 2013. CHIARA, V. L.; SICHIERI, R.; CARVALHO, T. S. F. Teores de ácidos graxos trans de alguns alimentos consumidos no Rio de Janeiro. Rev. Nutr., Campinas, v. 16, n. 2, p. 227-233, abr./jun. 2003.

CHRISTIE, W. W. Gas chromatography and lipids: a practical guide. Ayr, Scotland: The oil Press, 1989. 
CIABOTTI, S. et al. Avaliações químicas e bioquímicas dos grãos, extratos e tofus de soja comum e de soja livre de lipoxigenase. Ciênc. Agrotec., Lavras, v. 30, n. 5, p. 920929, set./out. 2006.

DANTAS, M. I. S. et al. Farinhas de soja sem lipoxigenase agregam valor sensorial em boloverRev. Ceres, Viçosa, v. 57, n. 2, p. 141-144, mar./abr. 2010.

DE ABREU, C. R. A. et al. Avaliação química e físico-química de bebidas de soja com frutas tropicais. Alim. Nutr., Araraquara, v. 18, n. 3, p. 291-296, jul./set. 2007.

ÁVILA, R. et al. Avaliação da composição centesimal e utilização na elaboração de biscoitos tipo cookie do resíduo da extração da fécula do mangarito. Revista Agrotecnologia, Ipameri, v. 1, n. 1, p. 21-32, 2010.

DUTCOSKY, S. D. Análise Sensorial de Alimentos. Curitiba: Universitária Champagnat, 1996. EL DASH, A.; GERMANI, R. Tecnologia de farinhas mistas: Uso de farinhas mistas na produção de biscoitos. Brasília: Embrapa - SPI, 1994. v. 6.

EMBRAPA SOJA. Receitas com soja: Biscoito de Coco e Farinha de Soja. Disponível em: <http://www.cnpso.embrapa.br/receitas/mostrar_receita.php?cod_receita=67> Acesso em: 14 mai. 2013.

EMBRAPA TRIGO. Trigo. Disponível em: <http://www.cnpt.embrapa.br/culturas/trigo/ index.htm> Acesso em: 18 jun. 2013.

FEDDERN, V. et al. Avaliação física e sensorial de biscoitos tipo cookie adicionados de farelo de trigo e arroz. Braz. J. Food Technol., Campinas, v. 14, n. 4, p. 265-272, out./ dez. 2011.

GARMUS, T. T. Avaliação sensorial de iogurte de morango com adição de farinha de linhaça. In: Semana de Integração Ensino, Pesquisa e Extensão (SIEPE), 2009.

GIOVANELLA, C.; SCHLABITZ, C.; DE SOUZA, C. F. V. Caracterização e aceitabilidade de biscoitos preparados com farinha sem glúten. Revista Brasileira de Tecnologia Agroindustrial, Ponta Grossa, v. 7, n. 1, p. 965-976, 2013.

KINOUCHI F. L. et al. Aceitação do “iogurte” de soja entre adolescentes. Alim. Nutr., São Paulo, v. 13, p. 131-142, 2002.

LIMA, C. C. Aplicação das farinhas de linhaça (Linum usitatissimum L) e Maracujá (Passiflora edulis Sims f. flavicarpa Deg.) no Processamento de Pães com Propriedades Funcionais. Tese (Mestrado em Tecnologia em Alimentos) - Centro de Ciências Agrárias da Universidade Federal do Ceará; Ceará, 2007.

LOPES, C. O. et al. Aproveitamento, composição nutricional e antinutricional da farinha de quinoa (Chenopodium quinoa). Alim. Nutr., Araraquara, v. 20, n. 4, p. 669675 , out./dez. 2009.

LOTTENBERG, A. M. P. Importância da gordura alimentar na prevenção e no controle de distúrbios metabólicos e da doença cardiovascular. Arq. Bras. Endocrinol. Metab., v. 53, n. 5, p. 595-607, 2009.

MACIEL, L. M. B.; PONTES, D. F.; RODRIGUES, M. C. P. Efeito da adição de farinha de linhaça no processamento de biscoito tipo cracker. Alim. Nutr., Araraquara, v. 19, n. 4, p. 385-392, out./dez. 2008. 
MARETI, M. C.; GROSSMANN, M. V. E.; BENASSI, M. T. Características físicas e sensoriais de biscoitos com farinha de soja e farelo de aveia. Ciênc. Tecnol. Aliment., Campinas, v. 30, n. 4, out./dez. 2010.

MARQUES, A. C. et al. Efeito da linhaça (Linum usitatissimum L.) sob diferentes formas de preparo na resposta biológica em ratos. Rev. Nutr., Campinas, v. 24, n. 1, p. 131-141, jan./fev. 2011.

MATOS, E. H. S. F. Dossiê técnico: Centro de Apoio ao Desenvolvimento Tecnológico da Universidade de Brasília. Processamento de Frutas Cristalizadas, 2007. Disponível em: <http://www.respostatecnica.org.br/dossie-tecnico/downloadsDT/MTA5>. Acesso em: 18 jun. 2013.

MIRANDA, M. Z.; EL-DASH, A. Farinha integral de trigo germinado. Características nutricionais e estabilidade ao armazenamento. Ciênc. Tecnol. Aliment., Campinas, v. 22, n. 3, p. 216-223, set./dez. 2002.

MITTELMANN, A. et al. Herança de caracteres do trigo relacionados à qualidade de panificação. Pesq. Agropec. Bras., Brasília, v. 35, n. 5, p. 975-983, mai. 2000.

MOLENA-FERNANDES, C.A. et al. Avaliação dos efeitos da suplementação com farinha de linhaça (Linum usitatissimum L.) marrom e dourada sobre o perfil lipídico e a evolução ponderal em ratos Wistar. Rev. Bras. Plantas Med., Botucatu, v. 12, n. 2, p. 201-207, abr./jun. 2010.

MORAES, K. S. et al. Avaliação tecnológica de biscoitos tipo cookie com variações nos teores de lipídio e de açúcar. Ciênc. Tecnol. Aliment., Campinas, v. 30, n. 1, mai. 2010.

OLIVEIRA, T. M.; PIROZI, M. R.; BORGES, J. T. S. Elaboração de pão de sal utilizando farinha mista de trigo e linhaça. Alim. Nutr., Araraquara, v. 18, n. 2, p. 141150, abr./jun. 2007.

PAUCAR-MENACHO, L. M. et al. Desenvolvimento de massa alimentícia fresca funcional com a adição de isolado protéico de soja e polidextrose utilizando páprica como corante. Ciênc. Tecnol. Aliment., Campinas, v. 28, n. 4, out./dez. 2008.

PEREZ, P. M. P.; GERMANI, R. Farinha mista de trigo e berinjela: características físicas e químicas. B.CEPPA, Curitiba, v. 22, n. 1, p. 15-24, jan./jun. 2004.

PERINI, J. A. L. et al. Ácidos graxos poli-insaturados n-3 e n-6: metabolismo em mamíferos e resposta imune. Rev. Nutr., Campinas, v. 23, n. 6, p. 1075-1086, nov./dez. 2010.

RAYFORD, W. E. et al. Analytical chemical support soybean uniform test analysis. USDA, Agricultural Research Service, Midwest Area, NCAUR, Peoria, 1994. p. 17-26.

REIS, F. R. Efeito dos processos de branqueamento e acidificação sobre a cor e a absorção de gorduras de batatas-palha. Dissertação (Mestrado em Tecnologia em Alimentos) Setor de Tecnologia da Universidade Federal do Paraná, Curitiba, 2007. 64f.

REPO-CARRASCO-VALENCIA, R. A.; SERNA, L. A. Quinoa (Chenopodium quinoa, Willd.) as a source of dietary fiber and other functional components. Ciênc. Tecnol.

Aliment., Campinas, n. 31, v. 1, p. 225-230, jan./mar. 2011.

RIBEIRO, L. F. Uso de espectroscopia no infravermelho e análise multivariada para previsão de ácidos graxos em linhaça dourada e marrom. Dissertação (Mestrado em Engenharia de Alimentos) - Setor de Tecnologia, Universidade Federal do Paraná, Curitiba, 2012. 
ROBERFROID, M. Functional food concept and its application to prebiotics. Digestive and Liver Disease, v. 34, n. 2, p. 105-10, 2002.

SAAD, S. M. I. Probióticos e prebióticos: o estado da arte. Revista Brasileira de Ciências Farmacêuticas, São Paulo, v. 42, n. 1, p. 1-16, mar. 2006.

SANDERS, M. E. Overview of functional foods: emphasis on probiotic bacteria. Int. Dairy J., Amsterdam, v. 8, p. 341-347, 1998.

SANTOS. H. M. C. et al. Desenvolvimento e caracterização físico-química de biscoitos com farinha de soja orgânica de cultivares especiais para a alimentação humana. In: V Jornada Acadêmica da Embrapa Soja. 2010.

SCHEUER, P. M. et al. Trigo: características e utilização na panificação. Revista Brasileira de Produtos Agroindustriais, Campina Grande, v. 13, n. 2, p. 211-222, 2011. SEIBEL, N. F.; BELÉIA, A. D. P. Características químicas e funcionalidade tecnológica de ingredientes de soja [Glycine Max (L.) Merrill]: carboidratos e proteínas. Braz. J. Food Technol., v. 12, n. 2, p. 113-122, abr./jun. 2009.

SILVA, F. D. et al. Elaboração de uma barra de cereal de quinoa e suas propriedades sensoriais e nutricionais. Alim. Nutr., Araraquara, v. 22, n. 1, p. 63-69, jan./mar. 2011. SILVA, M. R. Utilização tecnológica dos frutos de jatobá-do-cerrado e de jatobá-damata na elaboração de biscoitos fontes de fibra alimentar e isentos de açúcares. Ciênc. Tecnol. Aliment., Campinas, v. 21, n. 2, p. 176-182, maio/ago. 2001.

UNIVERSIDADE ESTADUAL DE CAMPINAS. Núcleo de Estudos e Pesquisas em Alimentação. TACO - Tabela Brasileira de Composição de Alimentos. Campinas: Universidade Estadual de Campinas, 2006. Disponível em: <http://www.unicamp.br/ nepa/taco/contar/taco_versao2.pdf> Acesso em: 17 jul. 2013.

VASCONCELOS, A. C. et al. Processamento e aceitabilidade de pães de forma a partir de ingredientes funcionais: farinha de soja e fibra alimentar. Alim. Nutr., Araraquara, v. 17, n. 1, p. 43-49, jan./mar. 2006.

VILLANUEVA, N. D. M.; PETENATE, A. J.; DA SILVA, M. A. A. P. Performance of the hybrid hedonic scale as compared to the traditional hedonic, self-adjusting and ranking scales. Food Quality and Preference, v. 16, n. 8, p. 691-703, dez. 2005.

VITTI, P.; GARCIA, E. E. C.; OLIVEIRA, L. M. Tecnologia de biscoitos. Campinas: Instituto de Tecnologia de Alimentos, 1988. 86 p. (Manual Técnico n. 1).

WANG, S. H. et al. Características sensoriais de leites de soja reconstituídos. Pesq. Agropec. Bras., Brasília, v. 34, n. 3, p. 467-472, mar. 1999.

. Absorção de água e propriedades espumantes de farinhas extrusadas de trigo e soja. Ciênc. Tecnol. Aliment., Campinas, v. 26, n. 2, p. 475-481, abr./jun. 2006. 